\title{
South African educational research journals
}

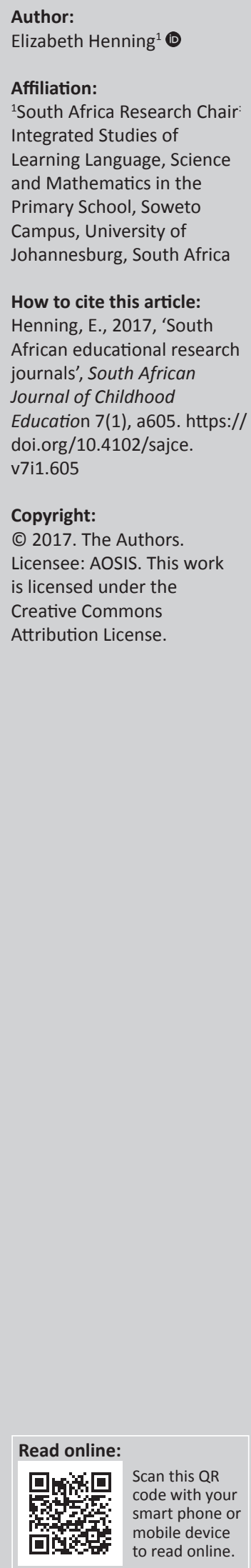

The South African educational research community consists of many branches, ranging from monitoring and evaluation (M\&E) consultancies, non-governmental organisations, practitioners at schools and in the business community, the science councils, education departments, nationally and in the provinces, and academic researchers at higher education institutions across many faculties.

Some of the publications coming from 'outside' universities and science councils are categorised as 'grey literature', while others from the 'scientific community' are viewed as 'real' research literature. Technical reports, officially referred to as 'grey literature', contain important findings and often lift their authors' $h$-index for alternative web visibility sky-high. I would plead for a shift in the definition of what counts as 'real' research, acknowledging the value of 'evaluation research', which has much to teach conventional 'academic' research in terms of design logic, just to mention one aspect.

The distinction between 'grey' and 'real' has created, I would argue, a conundrum for young academics who also do work for consulting agencies while they teach at university. Most of the country's new researchers labour on extended studies on a lonely and long journey, and only find a glimmer of visibility over a long time. Having been socialised into the academy in the conventional way, aiming to publish highly specialised work for an often small audience, new authors find it hard to achieve success along this route and opt for some M\&E work experience. As editor I have seen this happening over time: firstly, while getting the journal Education as Change off the ground in 1997 and getting it listed in the Social Sciences Citation Index (ISI, then Thomsen Reuters, now Clarivate) and subsequently with the founding of the South African Journal of Childhood Education in 2011. Established authors know when to submit their research to the most suitable journal. New authors need to find their home space and it takes time. Many younger researchers also find a part-time niche in evaluation work, where they produce both 'grey' and 'real' research. My sense is that this is a powerful cocktail.

Looking at the current more than 80 manuscripts under review and the 24 published in SAJCE this year, I see a promising trend. The journal has built an identifiable authorship and a readership that are crucial in the knowledge-making project of childhood education as a science and as an endeavour of development. Our articles present the work of the professions serving education during childhood and include the helping professions - ranging from speech and audiology, autism, teacher education, teaching, learning, policymaking, curriculum design, parenting and many others. Our authors work hard during the review and production process and are always willing to revise and resubmit. Our reviewers patiently reread resubmitted manuscripts. Our publisher works consistently to get the optimal article published online. What is more, the journal has led the way in open access education journals in South Africa.

We hope that when Clarivate evaluates the journal from 2018 onwards we will move from Emerging Sources Citation Index (ESCI) status to a journal worth listing in the Social Sciences Citation Index with a (even humble) beginning impact factor. We hope that our articles will achieve SCOPUS status with Elsevier. We also hope that our reviewer base will increase and continue to assist us in building knowledge and that the current (and future) indexing will add to the growth of a journal that is filling a very specific niche: publishing research and increasing knowledge about children in a generation when we will need much new knowledge. At the same time, we will also have to refine and redefine theories about learning and also about teaching as well as the role of screens in children's lives.

We will also make a big effort to assist authors of the 'grey' literature to convert their very important work to academic work. Lastly, we hope that current large-scale, early grades intervention studies 
of the Department if Basic Education will yield research articles that will fill many pages of this journal.

Reviewer and editing workshops will be conducted at the Centre for Education Practice Research at University of Johannesburg in 2018.

Announcements to follow in SAJCE.

\section{Acknowledgments}

We would like to acknowledge the grant of the Department of Higher Education, from whom we receive $50 \%$ of the publication and production cost of the journal through a Teaching and Learning Development Capacity Improvement Programme grant (2016-2020). 